\title{
Beyond screen time: Rethinking children's play in a digital world
}

\section{> Abstract}

The expert view is that screen time, when measured in hours, matters less than the content, context and connections associated with children's digital engagement. How are health visitors to advise parents accordingly? Drawing on new qualitative research with UK children, parents and carers and professionals who work with children, and on a national survey of 6-17-year-olds, this article asks whether the qualities of play that apply offline can also be applied online. The findings offer a language for parents, children and health visitors to talk about, and evaluate, when and how digital play benefits or undermines children's wellbeing.

\section{Key words}

$>$ Screen time > Digital games > Free play > Age-appropriate play

> Parental guidance

play, while also taking steps to avoid or mitigate the risks of other kinds. The concerns that motivated screen time advice still apply - outdoor play is important, as is bedtime, and parent-child interaction. However, as technology is here to stay, what advice is needed to avoid the problems and ensure that children get the best from it?

\section{Beyond screen time}

'Coronavirus lockdowns are worsening child obesity due to kids spending an extra FIVE HOURS per day in front of a screen' (Daily Mail, 2020).

Even before the first lockdown, and notwithstanding the views of the Daily Mail, child development experts were disputing whether, after all, the actual amount of children's screen time is really what matters to children's wellbeing. Their review of the evidence (Stiglic and Viner, 2019) led the Royal College of Paediatrics and Child Health (2019: 6) to conclude:

\section{1} health visitor visits a home and finds the older child clicking enthusiastically on the tablet while the toddler demands to join in. Is all well? What questions should the health visitor ask? What advice might they offer the parent?

For some years now, the focus has been on screen time (NHS, 2020). Parents are asked how long the child has been playing online, how they are trying to limit that time, and if they can take the tablet away at bedtime.

In this article, we argue for a different approach. We examine the qualities of free play that benefit children - when playing outside, at home with a cardboard box, with friends in the school playground - and ask whether these qualities can also be used to evaluate digital play. These qualities of play, we argue, offer a language for parents (and health visitors) to enable them to recognise the value of certain kinds of digital

Sonia Livingstone, London School of Political Science and Digital Futures Commission; and Kruakae Pothong, Digital Futures Commission (5Rights Foundation)

S.Livingstone@lse.ac.uk
'The risks from screen exposure should not be overstated. The evidence is relatively weak overall. Further, the magnitude of impact of screens is small on key health outcomes.'

Not only have the risks of screen time harms been overstated, except for children whose viewing is very high or whose lives are already troubled, but the effort to police children's screen time can be counterproductive, resulting in conflict or evasion rather than wellbeing (Livingstone and Blum-Ross, 2020). Thus, the expert consensus has been shifting away from counting screen time hours towards evaluating the content, context and connections that screen time brings (Livingstone and Franklin, 2018).

The evidence for the benefits of screen exposure is equivocal and, again, the particular circumstances matter. The emerging view is that if the content is age appropriate and developmentally informed, if the context includes active cognition and/or physical interaction, and if the activity builds connections, with parents, siblings, friends or grandparents, then digital engagement can be beneficial (Gee et al, 2017; Colvert, 2021). That is a lot of 'ifs'. How are parents to judge? 


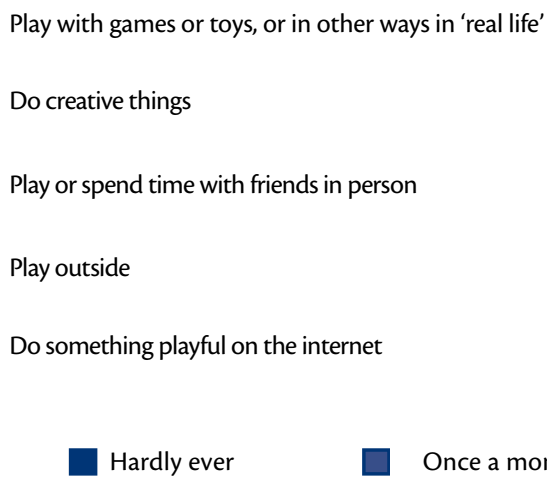

Hardly ever

Figure 1. How often do you do these things? (Digital Future Commission survey of 1033 UK 6-17 year olds)

The pandemic brought these expert debates firmly into the public domain, for the challenges of learning and working from home made parental efforts to control their children's screen time all but impossible. Now if not before, it has become obvious that using digital technologies is no longer a matter of choice but, rather, it is part of the very fabric of all our lives. Among 5-16 year olds, children's time online rose from 2 hours 54 minutes in 2019 to 3 hours 18 minutes in 2020, and parents reported finding this harder to control (Ofcom, 2021).

Our research shows what children's play looked like during June-July 2021, a time affected by periods of lockdown (Figure 1). While children play in many ways, playing online is the daily occurrence for many children, and playing outside and with friends in person, along with other forms of play, is less common. Moreover, as children get older, outdoor play is increasingly replaced by digital play (Family Kids and Youth 2021: 81).

Yet, research also shows that children's digital engagement is highly diverse, combining a mix of age-appropriate play and use of products designed for the general population (see Table 1). This suggests there is plenty of scope to guide them towards beneficial choices and that parents have a vital role to play in enabling young children's digital play (as prior literature confirms, Livingstone et al, 2015).

While the opportunities that technologies bring are vital, the risks have not gone away far from it. As parental anxieties about digital technologies shift from keeping track of time spent online to evaluating the content, context and connections that technology enables, new questions arise. While digital technology acts in crucial ways as both the conduit for opportunities and risks, it is also in itself risky by design
(5Rights Foundation, 2021). The business model of the big platforms is to maximise the profits of the attention economy through monetising our everyday online activities and the data traces they generate, and in so doing, little attention is paid to the needs of children who happen to use their products and services.

So, what should the health visitor ask the parent today? And what advice can they offer? When we asked a year 6 teacher how they would advise parents, we were told:

'I would struggle to know what's appropriate to recommend and I would have to go off and do my

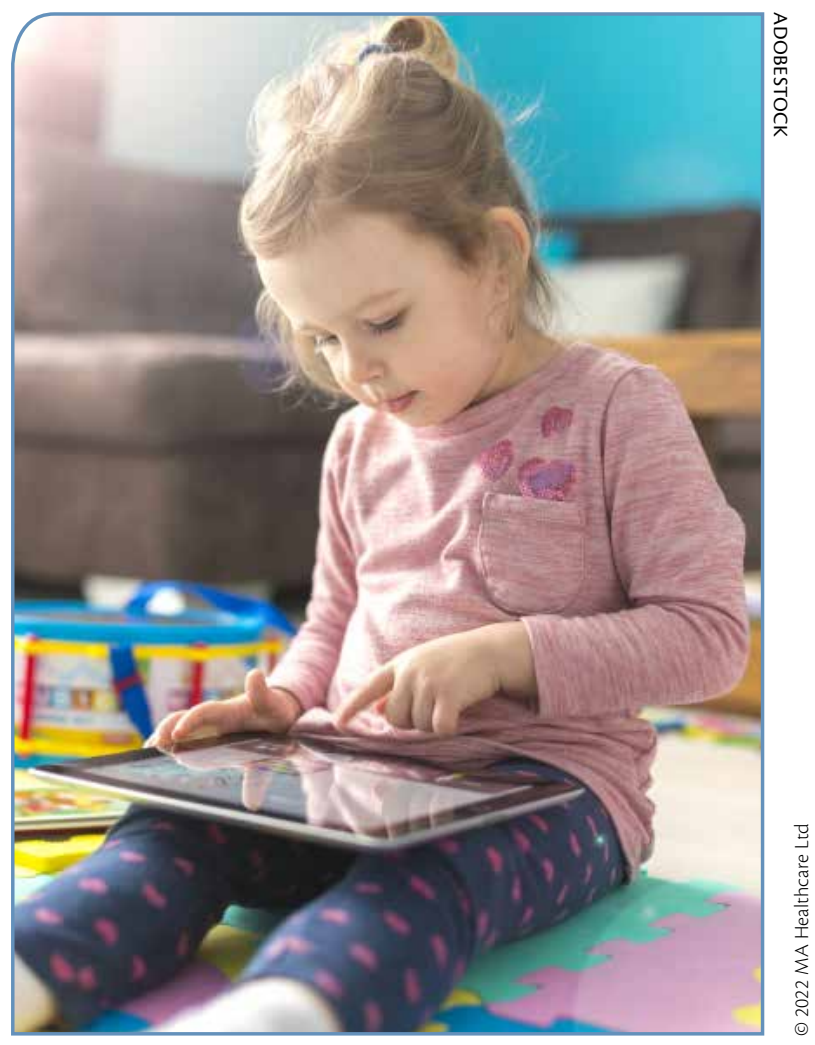




\begin{tabular}{|c|c|c|c|}
\hline Rank & $2-5$ years old & 6-9 years old & $10-12$ years old \\
\hline $\begin{array}{l}1 \\
2 \\
3 \\
4 \\
5 \\
6 \\
7 \\
8 \\
9 \\
10\end{array}$ & $\begin{array}{l}\text { CBeebies Storytime (47\%) } \\
\text { CBeebies Playtime app (45\%) } \\
\text { CBeebies Go Explore (43\%) } \\
\text { BBC iPlayer (41\%) } \\
\text { CBeebies Get Creative (37\%) } \\
\text { YouTube Music (34\%) } \\
\text { BBC Bitesize (30\%) } \\
\text { Angry Birds (29\%) } \\
\text { Mario Game (any) (28\%) } \\
\text { LEGO Life (28\% }\end{array}$ & $\begin{array}{l}\text { Roblox (50\%) } \\
\text { Minecraft (47\%) } \\
\text { BBC iPlayer (42\%) } \\
\text { YouTube Music (39\%) } \\
\text { Mario Game (any) (39\%) } \\
\text { Amazon (33\%) } \\
\text { WhatsApp (33\%) } \\
\text { Among Us (31\%) } \\
\text { Fortnite (31\%) } \\
\text { TikTok (31\%) }\end{array}$ & $\begin{array}{l}\text { WhatsApp (69\%) } \\
\text { TikTok (56\%) } \\
\text { Fortnite (54\%) } \\
\text { Minecraft (51\%) } \\
\text { Roblox (51\%) } \\
\text { BBC iPlayer (45\%) } \\
\text { Facebook (44\%) } \\
\text { YouTube Music (44\%) } \\
\text { Amazon (44\%) } \\
\text { Snapchat (42\%) }\end{array}$ \\
\hline
\end{tabular}

own research ... I probably would say to the parent I'm not too sure, I'd have to get back to you."

We need to know not only the problems linked to digital play but also what good digital play looks like. As one early years support worker said:

'If the value of play was better understood, then we wouldn't be treating children as commodities and things that have to race to become adults.'

\section{Researching children's play in a digital world}

Following a literature review on the nature and benefits of play (Cowan, 2020) and another on the pros and cons of digital play (Colvert, 2021), we conducted online family discussions with parents and children aged 3-18 along with small focus groups with professionals who work with children, and with children themselves (Pothong and Livingstone, 2021).

We first asked what the adults and children do for fun and then to compare their playful experiences with the illustrations of qualities of play identified in our first literature review (Cowan, 2020). Next, we asked both adults and children how these qualities of play manifest in a digital world and what needs to change.

The illustrations allowed us to engage children as young as 3 years old, with their parents, in a conversation about their playful experiences. As Figure 2 suggests, sometimes we invited children to draw or describe through playing with toys how they have fun using digital devices.

\section{The qualities of free play in a digital world}

Concerned that the public discourse about digital games has become hackneyed, our research sought an ambitious vision for children's digital play to match that of, say, society's expectations for digital education. We found that asking people for their views on free play generates a more exciting agenda of hopes and expectations than asking for their views on digital games.

We learned that what is valuable about play is that it is intrinsically motivated, voluntary, openended, imaginative, stimulating, emotionally resonant, social, diverse, risk-taking, safety, brings a sense of achievement and is immersive. These qualities provide the basis of a language to describe what 'good' play looks like in a digital world. This can be useful for policymakers and designers who determine the opportunities available for children and have the power to enrich them.

It can be helpful for professionals who work with families to identify what children enjoy and what benefits them, and to guide parents in understanding and supporting their children's digital lives. For example, can we learn from children's love of hide and seek to think creatively

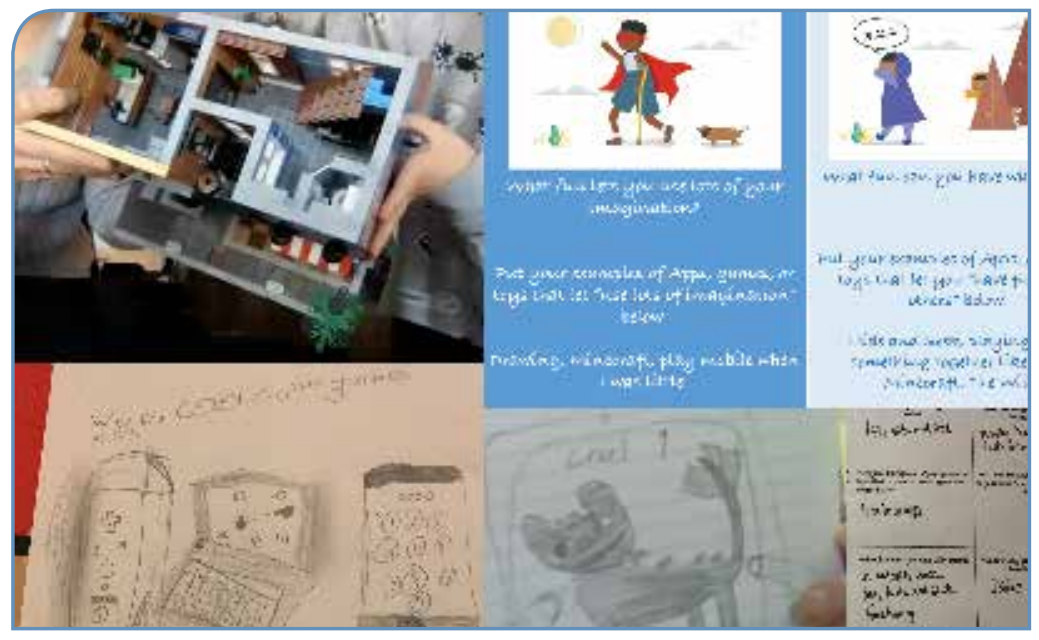

Figure 2. Children's drawings of play using digital devices 


\section{Box 1. Asking about 12 qualities of free play with digital products}

Using these 12 qualities of play, parents could be encouraged to ask their child questions about their play - and they could reflect on their own digital play. As conversation starters, these could build digital literacy and enable parent-child digital engagement.

1. Intrinsically motivated: Do you play like that because you want to or because others expect you to?

2. Voluntary: Can you start and stop playing when you want to, even when you've had enough?

3. Open-ended: When you play like that, can you make up what happens next?

4. Imaginative: Do you get to use your imagination when you play like that?

5. Stimulating: Do you feel excited and thrilled from the challenge when playing like that?

6. Emotionally resonant: Do you have different feelings when playing like that?

7. Social: Do you enjoy talking with other people about playing like that?

8. Diverse: Can you play in different ways that are important to you?

9. Risk taking: Can you be naughty, cheeky or break some rules without being told off when playing?

10. Safety: Do you feel safe when you play like that?

11. Sense of achievement: Do you feel that you've achieved something after playing like that?

12. Immersive: Do you feel like you're in a different world when playing like that? about digital technologies in unconventional ways? A mother and creative professional said:

'My 8 year old was playing on Zoom ... All the kids, they all have access to the screen and they're, sort of, playing hide and seek or catch, tag, so someone has to draw, and someone has to be the eraser.'

A playful interaction with digital technology can also generate emotional resonance, observed a social care manager and mother of two young children:

'We work with people from 0 to 100 ... and it doesn't matter the age of the person or what condition they are ... nine times out of 10, the stop-motion animation people want to make is either a person being brutally murdered or a fart joke. And they all scream with laughter.'

Talking of play offline, a mother and drama educator said:

'Play often feels chaotic when it's viewed from the outside ... They're hunting a giant squid, or they're pharaohs. That's when they have their biggest moments of joy.'

Does this also happen online? Could it? And what is the optimal role for parents? A childminder explained to us that outside play 'is about a lot of the time me not being involved,

\section{(Age apppropriate) Is good for people my age} (Intergenerational) Can be played or used together by people of different ages (Onboarding) It is easy for new users to understand to play or use (Contact) Gives me control over who can contact me through the app (Privacy) Gives me control over what other people see about me (Creative) Gives me ways to be creative

(Flexible) Gives me plenty of ways to change how it can be used (Variety) Offers different kinds of activities when using the app (Communication) Lets me chat or message people in the app (Transparent) Gives me information so I can understand how it works (Pathways) Gives me clues or instructions on how to get better at playing (Needs high tech) Needs a fast computer or internet connection to play or use (Compulsive) It can be hard to stop playing using

(Advertising) Included adverts for things to buy or do

(Excludes people ) Some people can feel excluded when playing or using (Provides help) Can help me if something upsetting happens (Commercial) Shows me things to spend real money in the app (Hateful) Sometimes I see people saying nasty things

(Transmedia) Can be played or used along with objects in my home, such as ... (Hybrid) Can be used to get me to move my body about or do exercise (Shares data) Shares my information with other apps or businesses (Expensive) It is too expensive for me to use fully

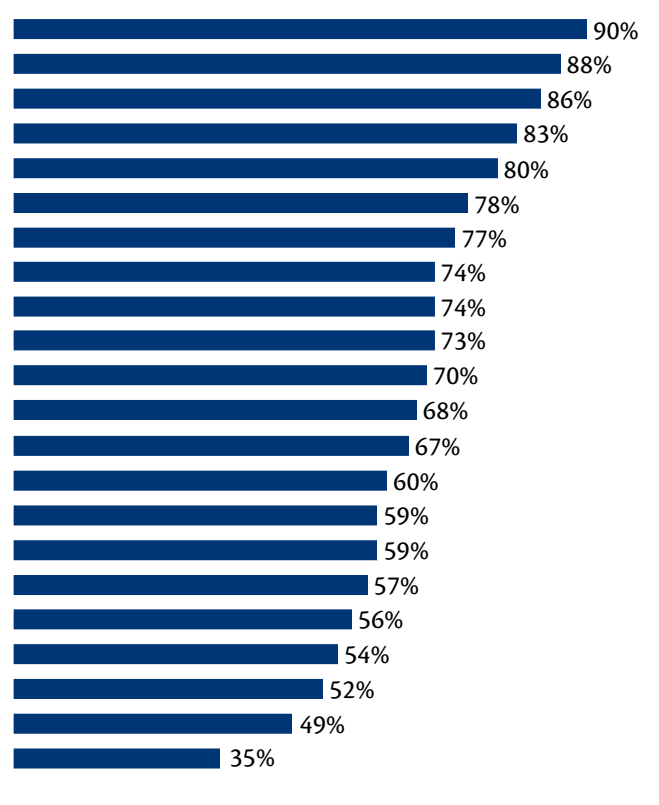

Figure 3. Digital Future Commission survey of 687 UK 10-17 year olds who were asked to judge the features of the digital products they play with 
is the children entirely leading their own play.' She added that she stays nearby, but not too near, leaving us to wonder how this could this be enabled for children's digital play.

We also wondered if we can encourage parents to enable ways of playing online that are imaginative and open-ended, or sociable and emotionally meaningful. Can this, further, provide a constructive alternative for when children feel compelled to continue playing even when they have had enough? In Box 1, we briefly set out what we mean by the 12 qualities of play, phrasing them as questions to ask in families.

\section{Consider play with Minecraft}

One game that children often told us they enjoyed is Minecraft, which is played by four in $10 \mathrm{UK}$ children aged 2-17. A five-year old boy said, 'It's ...building Lego isn't it, because ... Lego blocks look like Minecraft blocks.' A 7-year-old girl told us that she enjoyed Minecraft because of:

\section{'the excitement of exploring and finding out things} ... once, I saw a rock ... and I hit it with a pickaxe. But then it turned into an iron golem and ... it started chasing me around the village.'

In our national survey of UK 6-17-year-olds, children described the qualities of their play with Minecraft as coming close to the kind of child-led, open-ended imaginative play that children want and need, even resembling the kinds of offline play that many professionals would positively recommend for children. Minecraft play is seen as diverse (93\% agree), imaginative (92\%), openended (91\%), immersive (90\%), offering a sense of achievement (90\%), stimulating (89\%), social (89\%) and offering emotional resonance (75\%).

However, children also experienced play with Minecraft as less intrinsically motivated (50\%) or voluntary $(29 \%)$ than it could be. It was not always safe $-36 \%$ agreed that playing with Minecraft 'can sometimes bother or upset me', although other forms of digital play we asked about were seen as more problematic: Fortnite (54\%), WhatsApp (48\%), Nintendo Wii (48\%), Zoom (47\%), Roblox (46\%), TikTok (43\%) and YouTube (39\%) were all rated more highly. Interestingly, not only do children see Minecraft as the safest, but they are more confident in taking risks in that game (54\%) than with other apps.

Society instinctively understands the offline relationship between risk taking and safety. Can we guide parents to provide the kind of safety that enables, rather than prevents, children's

\section{Key points}

- Research suggests that evaluating the content, context and connections facilitated by digital engagement matters more than children's screen time measured in hours

- This article offers a language for professionals and for parents and carers to discuss and evaluate the quality of children's digital play, informed by 12 qualities of free play known to benefit children's development

- Qualitative and quantitative research shows how these qualities apply to children's digital play, taking Minecraft as an example. This offers a positive play experience but is less voluntary or safe than it could be

- The survey also reveals the features of digital products that children play: for older children especially, parents could be encouraged to discuss these with their children to stimulate shared evaluation of play possibilities

exploration and experimentation online, and that builds their digital resilience rather than concentrates on monitoring and restricting them for their own safety? Building resilience is vital for child development and as this involves facing and coping with a degree of adversity, it is a crucial challenge for our risk-averse age.

\section{Getting into the detail of digital contents, contexts and connections} While even a generally beneficial game like Minecraft brings risks as well as opportunities, so does playing hopscotch in the street or tag in the park. In other words, in addition to the challenge of identifying the pros and cons of digital play is the further challenge of finding the right balance for the individual child. This depends, in part, on the child and their circumstances of course, but it also depends on the nature of the game and, in relation to digital technologies, even describing this can be complex.

In our survey, we asked the 10-17 year olds about the features of the digital products and services they play with (Figure 3 ). This suggests a constructive language for parents to engage with their children, if they are old enough. Some of these features are likely to be digital enablers and others are barriers to free play.

\section{"It can be helpful for professionals who work with families to identify what children enjoy and what benefits them, and to guide parents in understanding and supporting their children's digital lives «}


Since we found children had views about the digital products and services they use on these features, these features could also provide a language for insightful conversation between parent and child.

\section{Recommendations}

- Health visitors could draw on the qualities of play as conversation starters for parents and children. These can facilitate a shared language for identifying what's beneficial about digital engagement, and what can be problematic.

- Getting beyond talk of 'screens' or 'going online', parents could also be advised to develop a language to discuss the features of digital products and services. This can help recognise what children as well as parents enjoy or find worrying.

- Finding ways for families to share playful ways to engage with digital technologies can be productive, helping to overcome the conflicts that can result from efforts to police screen time.

5Rights Foundation (2021) Risky by design. www.riskyby.design/ introduction (accessed 6 January 2022)

Colvert A (2021) The Kaleidoscope of Play in a Digital World: A Literature Review. Digital Futures Commission - 5Rights Foundation. https:// digitalfuturescommission.org.uk/wp-content/uploads/2021/06/DFCDigital-Play-Literature-Review.pdf (accessed 6 January 2022)

Council on Communications and Media (2016) Media and young minds. Pediatrics 138(5): e20162591-e20162591. https://publications.aap.org/ pediatrics/article/138/5/e20162591/60503/Media-and-Young-Minds (accessed 6 January 2022)

Cowan K (2020) A Panorama of Play: A Literature Review. Digital Futures Commission - 5Rights Foundation. https://digitalfuturescommission. org.uk/wp-content/uploads/2020/10/A-Panorama-of-Play-A-LiteratureReview.pdf (accessed 6 January 2022)

Dubit Trends (2021) Dubit Trends. www.dubitlimited.com/insights/trends (accessed 6 January 2022)

Family Kids and Youth (2021) Playful by Design survey report and findings. Digital Futures Commission. https://digitalfuturescommission.org.uk/ play-in-a-digital-world (accessed 6 January 2022)

Livingstone S, Blum-Ross A. Parenting for a digital future: How hopes and fears about technology shape children's lives. Oxford University Press; 2020

Livingstone S, Pothong K (2021) Playful by Design: A Vision of Free Play in a Digital World. Digital Futures Commission (5Rights Foundation). https://digitalfuturescommission.org.uk/wp-content/uploads/2021/11/ A-Vision-of-Free-Play-in-a-Digital-World.pdf (accessed 6 January 2022) Livingstone S, Marsh J, Plowman L, Ottovordemgentschenfelde S, Fletcher-Watson B. (2015) Young children (0-8) and digital technology: A qualitative exploratory study - National report - UK. http://eprints.lse. ac.uk/63378 (accessed 6 January 2022)

Livingstone $S$, Franklin K. Families with young children and 'screen time.' Journal of Health Visiting. 2018;6(9):434-439

NHS Greater Glasgow and Clyde (2020) Screen Time Guidelines. www. nhsggc.org.uk/about-us/professional-support-sites/screen-time/screentime-guidelines (accessed 6 January 2022)

Ofcom (2020/21) Children and parents: media use and attitudes report. www.ofcom.org.uk/_data/assets/pdf_file/0025/217825/children-andparents-media-use-and-attitudes-report-2020-21.pdf (accessed 6 January 2022)

Pothong K, Livingstone S (2021) Navigating the ethical challenges of consulting children via Zoom. Digital Futures Commission blog https:// digitalfuturescommission.org.uk/blog/navigating-the-ethical-challengesof-consulting-children-via-zoom (accessed 6 January 2022)

Royal College of Paediatrics and Child Health (2019) The health impacts of screen time: a guide for clinicians and parents. www.rcpch.ac.uk/ resources/health-impacts-screen-time-guide-clinicians-parents (accessed 6 January 2022)

Stiglic N, Viner RM. Effects of screentime on the health and well-being of children and adolescents: A systematic review of reviews. BMJ Open. 2019;9(1):1-15. https://bmjopen.bmj.com/content/bmjopen/9/1/ e023191.full.pdf

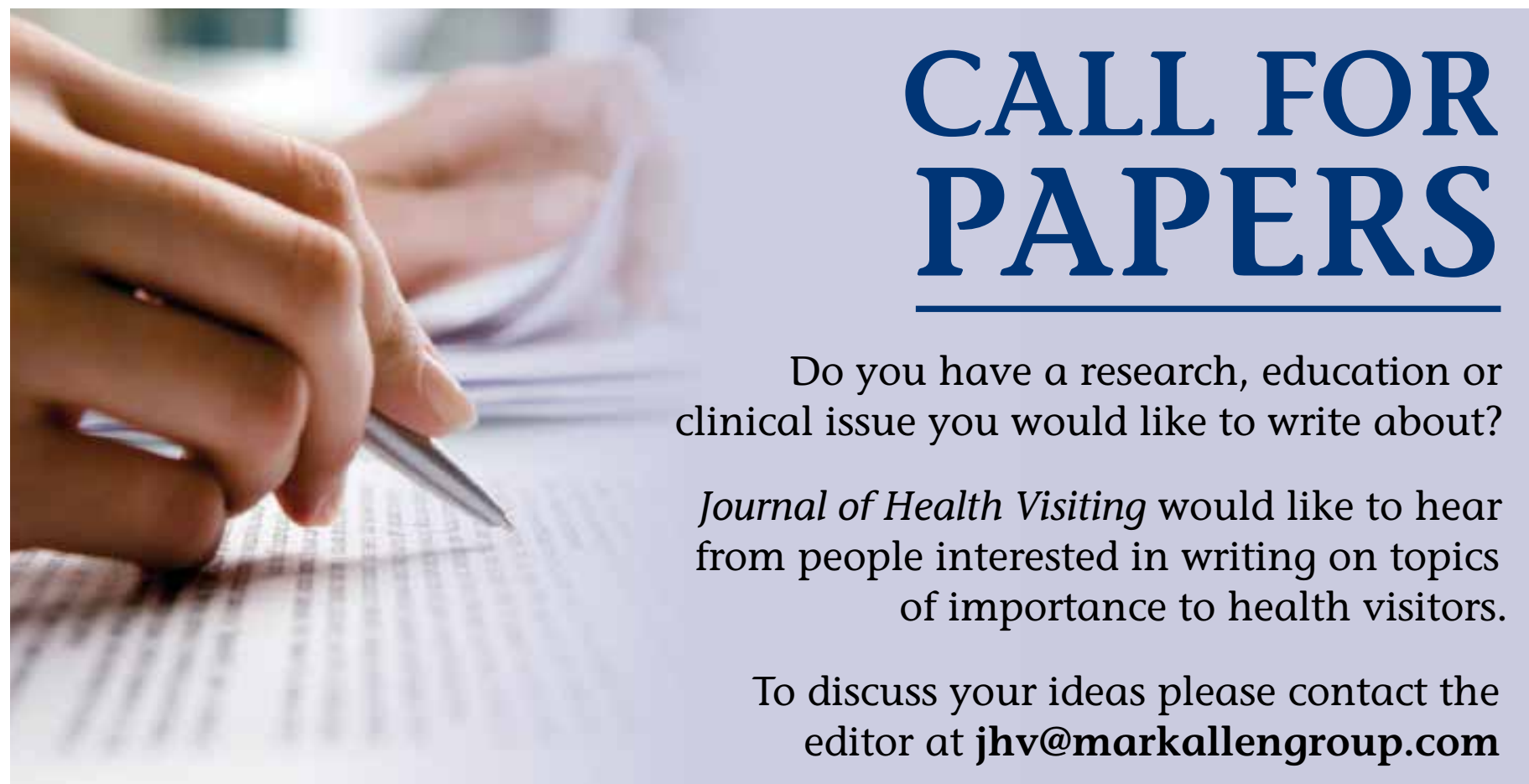

